Available online at https:/jurnal.stmikroyal.ac.id/index.php/jurdimas

\title{
PEMANFAATAN DIGITALISASI UNTUK PEMESANAN ONLINE KULINER KERUPUK BASAH PADA WARUNG AGDI BENGKAYANG
}

\author{
Noviyanti. $\mathbf{P}^{\mathbf{1}^{*}}$, Yuliana ${ }^{1}$ \\ ${ }^{1}$ Program Studi Teknologi Informasi, Institut Shanti Bhuana \\ email:*noviyanti@shantibhuana.ac.id
}

\begin{abstract}
The development of technology in this modern era makes every person or individual must be responsive to adapt to technology in order to continue to develop and be productive in social, economic, and others. Technology can facilitate daily activities in buying and selling transactions, buying or selling goods can be easily done anywhere. Various types of sales can be made by the community, especially in the culinary field. Warung Agdi is a wet cracker culinary, this culinary is a typical culinary of Kapuas Hulu but is in demand by almost all districts, one of which is Bengkayang Regency. However, problems were found in the culinary business of Agdi's stall. Where customers have to wait for their orders to be made because for processing wet crackers at Agdi's stall, they must first steam the wet crackers before serving, so it takes time for customers to wait for their orders to be ready. Buying and selling activities at Agdi stalls are also still carried out conventionally, so not many people know about the wet cracker culinary owned by Agdi's stall owners. Based on these existing problems, a solution is needed so that Agdi stalls can take advantage of technology by making online ordering applications which can later be used by Agdi stall owners to sell and can also be used as a means of promotion.
\end{abstract}

Keywords: AGDI stall; culinary; digitization; kerupuk basah; online ordering

\begin{abstract}
Abstrak: Perkembangan teknologi di zaman modern ini membuat setiap orang atau individu harus tanggap beradaptasi dengan teknologi agar tetap dapat berkembang dan produktif dalam sosial, ekonomi, dan lain-lain. Teknologi dapat memudahkan aktifitas sehari-hari dalam transaksi jual beli, kegiatan membeli atau menjual barang dapat dengan mudah dilakukan di mana saja. Berbagai jenis penjualan dapat dilakukan masyarakat, khususnya dibidang kuliner. Warung Agdi merupakan kuliner kerupuk basah, kuliner ini merupakan kuliner khas Kapuas Hulu namun diminati hampir seluruh Kabupaten, salah satunya Kabupaten Bengkayang. Namun, ditemukan permasalahan pada usaha kuliner warung Agdi. Diman pelanggan harus menunggu pesanan mereka dibuat karena untuk pengolahan kerupuk basah pada warung Agdi harus mengkukus kerupuk basah terlebih dahulu sebelum dihidangkan, sehingga perlu waktu bagi pelanggan untuk menunggu pesanannya siap. Kegiatan jual beli pada warung Agdi juga masih dilakukan secara konvensional, sehingga tak banyak yang mengetahui kuliner kerupuk basah yang dimiliki pemilik warung Agdi. Berdasarkan permasalahan yang ada tersebut, diperlukan solusi untuk agar warung Agdi dapat memanfaatkan teknologi dengan pembuatan aplikasi pemesanan online yang nantinya dapat digunakan pemilik warung Agdi ini untuk menjual dan dapat pula digunakan sebagai sarana promosi.
\end{abstract}

Kata kunci: digitalisasi; kerupuk basah; kuliner; pemesanan online; warung agdi

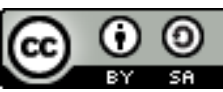


Jurdimas (Jurnal Pengabdian Kepada Masyarakat) Royal

Vol. 5 No. 1, Januari 2022, hlm. 33 - 38

Available online at https:/jurnal.stmikroyal.ac.id/index.php/jurdimas

\section{PENDAHULUAN}

Warung Agdi Bengkayang merupakan usaha kecil yang menjual kerupuk basah. Kerupuk basah merupakan kuliner yang berasal dari Kapuas Hulu provinsi Kalimantan Barat. Kerupuk basah merupakan kuliner hasil olahan dari ikan dan tepung yang sangat diminati masyarakat baik dari dalam Kapuas Hulu maupun dari luar Kapuas Hulu termasuk masyarakat Bengkayang. Warung Agdi dalam penjualan masih bersifat kovensional, artinya pembeli kerupuk basah harus datang dan memesan kerupuk basah secara langsung ke Warung Agdi. Kerupuk basah yang dipesan pelanggan terlebih dahulu dipanaskan dengan cara dikukus dan selanjutnya di sajikan ke pembeli, dengan begitu perlu waktu untuk pelanggan dalam menikmati kerupuk basah tersebut.

Seiring berjalannya waktu teknologi semakin berkembang, sehingga penjualan yang bersifat konvensional mulai ditinggalkan. Banyak yang telah beralih kepenjualan secara online. Seperti pada penelitian (Defrina \& Lestari, 2017), yang membuat Aplikasi Pemesanan Makanan dan Minuman Online Berbasis Mobile Browser pada Restoran Tiga Saudara. Aplikasi ini dibuat untuk menunjang kualitas pelayanan restoran dalam melakukan pemesanan. Dijelaskan pula bahwa pemesanan makanan dan minuman pada restoran tersebut dulunya dilakukan secara manual. Terdapat kekurangan dari pemesanan secara manual tersebut, diantaranya pelanggan kadang harus menunggu kedatangan pelayan untuk melakukan pemesanan dan terjadi juga pemesanan double. Oleh karena itu dilakukan penelitian tersebut untuk mempermudah proses pemesanan makanan dan minuman pada restoran tiga saudara. Penelitian lain yang dilakukan oleh (Alfiah, Tarmizi, \& Junidar, 2020), melakukan Perancangan Sistem ECommerce untuk Penjualan Pakaian pada Toko A\&S. Penelitian tersebut bertujuan untuk membantu masyarakat agar dapat menghemat waktu dalam membeli pakaian karena bisa dibeli secara online.

Menurut penelitian (Nugroho, 2016) E-Commerce merupakan bagian dari perkembangan teknologi dalam melakukan jual-beli secara online. Penelitian yang dilakukan oleh (Nugroho, 2016) melakukan Perancangan Sistem Informasi Penjualan Online Studi Kasus Tokoku bertujuan untuk membantu Tokoku dalam meningkatkan nilai penjualan.

Teknologi internet dalam bisnis digunakan untuk melakukan pertukaran informasi, media promosi, dan komunikasi yang dapat dilakukan secara online. Pemanfaatan digital marketing bagi usaha mikro, kecil, dan menengah pun menjadi salah satu pilihan di era masyarkat ekonomi Asean (Febriyantoro \& Arisandi, 2018). Dengan memanfaatkan internet pelaku usaha dapat memberikan informasi yang secara berkala dan akurat terkait dengan produk yang dimiliki untuk dapat ditawarkan pada konsumen.

Pemanfaatan digital teknologi tidak hanya menghantar kita kepada penggunaan aplikasi saja, namun dapat membantu dalam hal promosi. Seperti penelitian yang dilakukan oleh (Maulana, Susilo \& Riyadi, 2015) yang membahas tentang Implementasi $E$ Commerce sebagai Media Penjualan online. penelitian tersebut bertujuan untuk menjadikan media penjualan tersebut sebagai bagian dari kegiatan promosi, khususnya Toko Pastbrik kota Malang yang menjual jenis barang 
Available online at https:/jurnal.stmikroyal.ac.id/index.php/jurdimas

elektronik. Selain itu, peman-faatan digital teknologi juga dapat membantu dalam memberikan kemudahan dan kenyamanan kepada para peng-gunanya (Aryanto \& Tjendrowasono, 2012).

Berdasarkan penjabaran dan penelitian yang telah diteliti tersebut Warung Agdi perlu mengikuti teknologi terkini untuk dapat menjual produk makanannya, dengan harapan dapat dengan mudah menjual kuliner tersebut tanpa terkendala waktu, tempat dan lain sebagainya. Aplikasi pemesanan online dirasa perlu dimanfaatkan untuk warung-warung kecil seperti Warung Agdi ini.

Aplikasi pemesanan online dapat digunakan untuk menjual dan dapat juga sebagai sarana promosi agar produk memiliki jangkauan yang lebih luas. Aplikasi yang digunakan pun cukup bermodalkan dengan internet yang dimana internet menjadi salah satu kebutuhan sehari-hari bagi masyarakat. Aplikasi pemesanan online ini juga diharapkan dapat memudahkan pembeli dalam memesan kerupuk basah serta menghemat waktu.

\section{METODE}

Adapun metode pelaksanaan
yang dilakukan pada kegiatan
pengabdian masyarakat ini berupa dipusi
iptek, dengan pelaksanaan kegiatan
pengabdian yang dapat dijabarkan
sebagai berikut:

Analisis Masalah: Melakukan analisis masalah yang terdapat pada warung Agdi. Proses analisis masalah dilakukan dengan berkoordinasi dengan pemilik warung Agdi. Dijelaskan oleh beliau bahwa pemesanan kerupuk basah memang dilakukan secara konvensional dan kadang harus membuat pelanggan menunggu hingga pesanan siap disajikan.

Melakukan Pertemuan: Selanjutnya akan dilakukan pertemuan dengan topik pembahasan kegiatan pengabdian yang akan dilakukan.

Mencari Solusi: Selanjutnya mencari solusi untuk masalah yang dialami pemilik warung Agdi.

Perancangan Sistem: Perancangan yang dilakukan pada aplikasi pemesanan online kerupuk basah ini terdiri dari perancangan database yang dibuat menggunakan MySQL

Implementasi: Melakukan implementasi dan melihat apakah aplikasi sudah dapat digunakan untuk melakukan pemesanan online atau masih terdapat masalah yang harus diatasi. Setelah semuanya siap, perancangan maupun implementasi maka produk sudah dapat digunakan dan dapat disosialisasikan kepada pemilik warung Agdi. Hasil akhir yang diperoleh dari kegiatan pengabdian ini adalah produk berupa aplikasi pemesanan online.

\section{PEMBAHASAN}

Pengabdian yang dilakukan pada Warung Agdi Bengkayang bertujuan untuk memudahkan pemesanan makanan dan sebagai bentuk promosi agar usaha kuliner Warung Agdi Bengkayang ini dapat berkembang dan dikenal oleh masyarakat sekitar. Pengabdian dilakukan juga berdasarkan wawancara langsung yang dilakukan dengan pemilik usaha kuliner kerupuk basah tersebut. Pemilik usaha tersebut menyetujui kerjasama yang ditawarkan dari pihak kampus Institut Shanti Bhuana. Pada Gambar 1 merupakan persetujuan kerjasama antara pihak kampus Institut Shanti Bhuana dengan pemiliki Warung 
Available online at https:/jurnal.stmikroyal.ac.id/index.php/jurdimas

Agdi Bengkayang. Sebagai salah satu bentuk penerapan ilmu pengetahuan teknologi dan kontribusi terhadap kegiatan pengabdian masyarakat, maka pada kesempatan ini penulis memanfaatkan digitalisasi pemesanan online kerupuk basah pada Warung Agdi bengkayang dengan membuat sebuah aplikasi sederhana berbasis web yang dapat digunakan oleh pemilik usaha kuliner kerupuk basah Warung Agdi Bengkayang.

Aplikasi dirancang sedemikian rupa untuk selanjutnya dapat digunakan oleh pemilik kuliner kerupuk basah Warung Agdi Bengkayang. Pada aplikasi ini memiliki dua sisi, yaitu sisi admin dan sisi pengguna. Admin adalah pemilik usaha kuliner kerupuk basah. Pada kegiatan pengabdian kepada masyarakat tersebut, penulis berkewajiban pula mensosialisasikan cara menggunakan aplikasi pemesanan online ini. Kegiatan sosialisasi dilakukan dengan melakukan pertemuan secara langsung dengan pihak pemilik Warung Agdi Bengkayang (Gambar 2). Pada gambar 2, merupakan kegiatan mensosialisasikan aplikasi pemesanan online. Pada aplikasi ter-sebut, pemilik Warung Agdi Beng-kayang dapat memasukkan berbagai produk makanan dan minuman yang dimiliki oleh Warung Agdi Bengkayang selain kerupuk basah, sehingga aplikasi ini dapat membantu pemilik warung baik dari segi penjualan maupun dari segi promosi produk makanan.

Pada gambar 3, merupakan tampilan daftar menu makanan yang dapat ditambahkan oleh pemilik kuliner kerupuk basah Warung Agdi Bengkayang. Jadi dapat dilihat pada Gambar 3 tersebut bahwa terdapat berbagai makanan dan minuman yang dapat diinputkan sesuai dengan yang tersedia pada Warung Agdi Bengkayang. Gambar 4 merupakan tampilan awal aplikasi pemesanan online kerupuk basah Warung Agdi Bengkayang. Untuk pengguna yang ingin melakukan pemesanan, maka pengguna harus registrasi dulu dan membuat akun pada aplikasi pemesanan online tersebut. Form registrasi pengguna dapat dilihat pada gambar 5. Gambar 5 merupakan form registrasi pengguna. Setelah peng-guna memiliki akun, maka pengguna dapat login dan dapat masuk pada daftar menu untuk melakukan pemesanan. Form login dapat dilihat pada Gambar 6. Untuk selanjutnya pengguna dapat melakukan pemesanan dengan mengklik tombol beli seperti terlihat pada Gambar 7 .

Gambar 8 merupakan tampilan pesanan pelanggan di sisi admin. Admin dapat mengetahui siapa yang memesan, kemudian terdapat pula tanggal pemesanan, dan total biaya pemesanannya. Kemudian admin dapat mengklik tombol detail untuk mengetahui apa saja yang dipesan oleh pembeli atau pengguna untuk kemudian admin menyiapkan pesanan pembeli. Gambar 8 merupakan daftar menu pembeli. Pengguna dapat memilih menu makanan dengan mengklik tombol beli kemudian setelah semua pesanan pengguna telah dipilih, maka pengguna dapat melakukan konfirmasi pesanan agar semua pesanan pembeli atau pengguna masuk ke sisi admin.

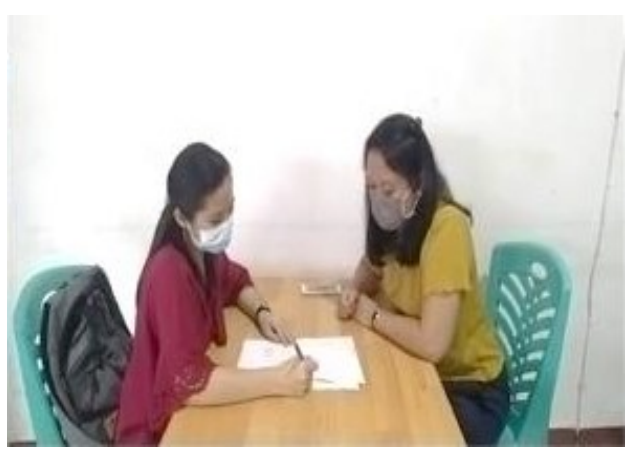

Gambar 1. Persetujuan Kerjasama 
Jurdimas (Jurnal Pengabdian Kepada Masyarakat) Royal

Vol. 5 No. 1, Januari 2022, hlm. 33 - 38

ISSN 2614-7912 (Print)

DOI: https://doi.org/10.33330/jurdimas.v5i1.1145

ISSN 2622-3813 (Online)

Available online at https://jurnal.stmikroyal.ac.id/index.php/jurdimas

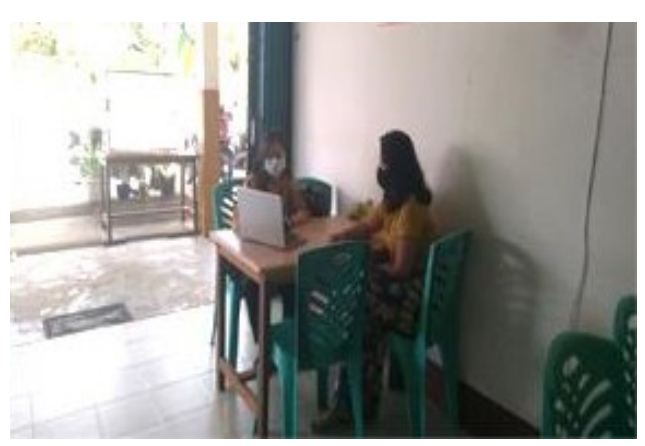

Gambar 2. Kegiatan Mensosialisasikan Aplikasi Pemesanan Online

KERUPUK BASAH WARUNG AGDI

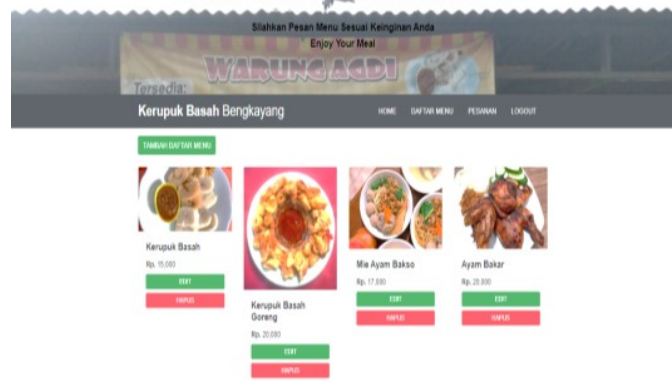

Gambar 3. Tampilan Daftar Menu Makanan

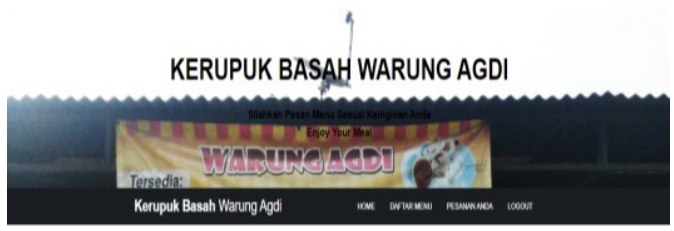

KERUPUK BASAH WARUNG AGD

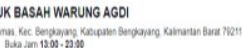

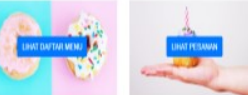

Gambar 4. Tampilan Awal Aplikasi Pemesanan Online

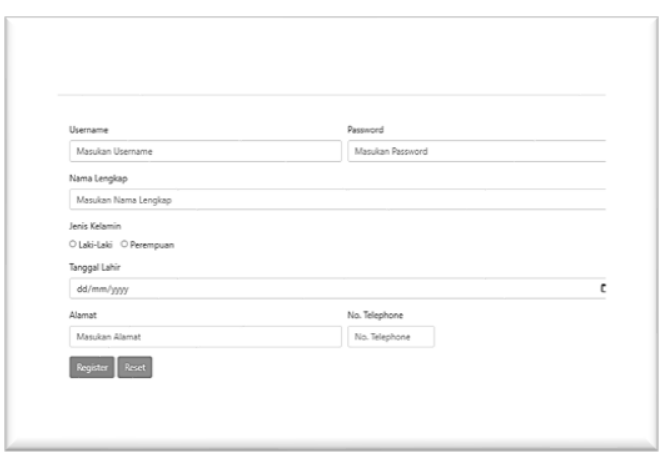

Gambar 5. Form Registrasi

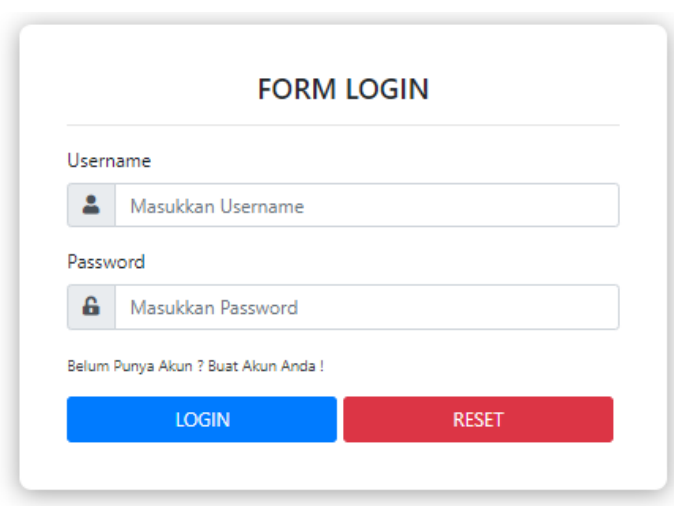

Gambar 6. Form Login

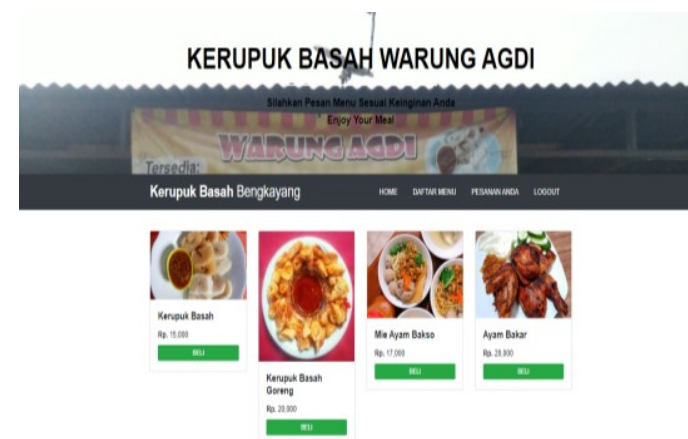

Gambar 7. Daftar Menu Pembeli

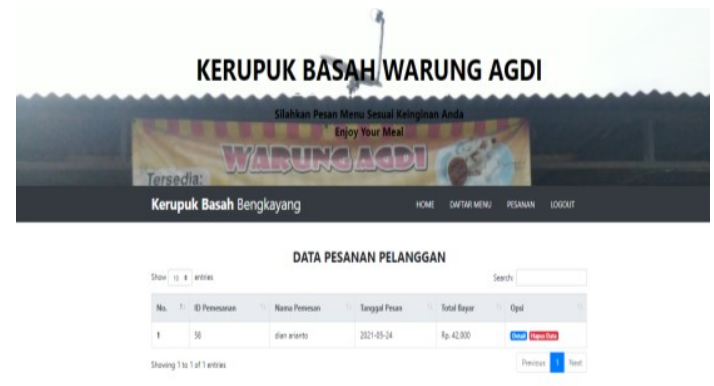

Gambar 8. Tampilan Pesanan Pelanggan di Sisi Admin

\section{SIMPULAN}

Pengabdian kepada masyarakat yang dilakukan pada Warung Agdi Bengkayang telah terealisasikan. Aplikasi pemesanan makanan dan minuman online berbasis mobile browser dirancang dapat digunakan oleh pemilik warung dan dapat dimanfaatkan dengan baik dari sisi penjualan maupun 
Jurdimas (Jurnal Pengabdian Kepada Masyarakat) Royal

Vol. 5 No. 1, Januari 2022, hlm. 33 - 38

ISSN 2614-7912 (Print)

DOI: https://doi.org/10.33330/jurdimas.v5i1.1145

ISSN 2622-3813 (Online)

Available online at https:/jurnal.stmikroyal.ac.id/index.php/jurdimas

dari sisi promosi produk. Dengan perkembangan tek-nologi saat ini, pemanfaatan digital menjadi pilihan yang membantu untuk dapat mengembangkan usaha kuliner masyarakat. Aplikasi yang dibuat masih memiliki kekurangan sehingga dapat dikembangkan lagi baik dari segi fitur maupun dari sisi pengembangan.

\section{DAFTAR PUSTAKA}

Alfiah, F., Tarmizi, R., \& Junidar, A. A. (2020). Perancangan Sistem ECommerce Untuk Penjualan Pakaian Pada Toko a\&S. ICIT Journal, 6(1), 70-81. https://doi.org/10.33050/icit.v6i 1.862

Arsyah, R. H., \& Juwita, A. I. (2021). Konvergensi Media dalam Pemasaran Produk Kerajinan Masyarakat desa Wisata Pariangan. Jurdimas (Jurnal Pengabdian Kepada Masyarakat) Royal, 4(1), 5964.

Aryanto, A., \& Tjendrowasono, T. I. (2012). Pembangunan Sistem Penjualan Online pada Toko Indah Jaya Furniture Surakarta. Journal Speed - Sentra Penelitian Engineering Dan Edukasi, 4(4), 56-62.

Defrina, D., \& Lestari, D. P. (2017). Aplikasi Pemesanan Makanan Dan Minuman Online Berbasis Mobile Browser Pada Restoran Tiga Saudara Aplication of Ordering Food and Beverages Online Based on Mobile
Browser on Tiga Saudara Restaurant. Jurnal Ilmiah Informatika Dan Komputer, 22(3), 158-170.

Febriyantoro, M. T., \& Arisandi, D. (2018). Pemanfaatan Digital Marketing Bagi Usaha Mikro, Kecil Dan Menengah Pada Era Masyarakat Ekonomi Asean. JMD: Jurnal Riset Manajemen \& Bisnis Dewantara, 1(2), 6176.https://doi.org/10.26533/jmd .v1i2.175

Maulana, S. M., Susilo, H., \& Riyadi. (2015). Implementasi ECommerce Sebagai Media Penjualan Online. Jurnal Administrasi Bisnis, 29(1), 1-9.

Nugroho, F. E. (2016). Perancangan Sistem Informasi Penjualan Online Studi Kasus Tokoku. Simetris : Jurnal Teknik Mesin, Elektro Dan Ilmu Komputer, 7(2), 717. https://doi.org/10.24176/simet.v $7 \mathrm{i} 2.786$

Yenni, Y., Utnasari, I., \& Rahmawati, M. (2021). Sosialisasi Pemanfaatan Teknologi Informasi Internet Berbasis Media Sosial Sebagai Usaha dan Transaksi. Jurdimas (Jurnal Pengabdian Kepada Masyarakat) Royal, 4(1), 1-6.

Yuliana, O. Y. (2000). Penggunaan Teknologi Internet Dalam Bisnis. Jurnal Akuntansi Dan Keuangan, 2(1), 36-52. https://doi.org/10.9744/jak.2.1. pp.36-52. 